\title{
(6) OPEN ACCESS \\ Trends in Scottish newborn screening programme for congenital hypothyroidism 1980-2014: strategies for reducing age at notification after initial and repeat sampling
}

\author{
Chourouk Mansour, ${ }_{1}^{1}$ Yasmine Ouarezki, Jeremy Jones, ${ }^{3}$ Moira Fitch, ${ }^{4}$ Sarah Smith, ${ }^{4}$ \\ Avril Mason, ${ }^{3}$ Malcolm Donaldson ${ }^{5}$
}

'Hôpital Universitaire d'Enfants Abderrahim Harouchi,

Casablanca, Morocco

${ }^{2}$ Etablissement Public

Hospitalier Hassen-Badi, ElHarrach, Algiers, Algeria

${ }^{3} \mathrm{NHS}$ Greater Glasgow and Clyde, Royal Hospital for Children, Queen Elizabeth University Hospital, Glasgow, UK ${ }^{4}$ Newborn Screening Laboratory, Queen Elizabeth University Hospital, Glasgow, UK

${ }^{5}$ Section of Child Health, Glasgow University School of Medicine, c/o Royal Hospital for Children, Glasgow, UK

\section{Correspondence to} Dr Malcolm Donaldson, Section of Child Health, Glasgow University School of Medicine, Glasgow G12 8 QQ, UK; malcolm.donaldson@glasgow. ac.uk

Received 10 October 2016 Revised 3 May 2017 Accepted 9 May 2017

Published Online First 9 June 2017

\section{CrossMark}

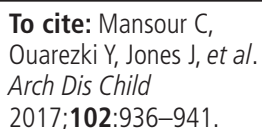

\section{ABSTRACT}

Objectives To determine ages at first capillary sampling and notification and age at notification after second sampling in Scottish newborns referred with elevated thyroid-stimulating hormone (TSH).

Subjects and methods Referrals between 1980 and 2014 inclusive were grouped into seven 5-year blocks and analysed according to agreed standards.

Results Of 2116132 newborn infants screened, 919 were referred with capillary TSH elevation $\geq 8 \mathrm{mU} / \mathrm{L}$ of whom 624 had definite (606) or probable (18) congenital hypothyroidism. Median age at first sampling fell from 7 to 5 days between 1980 and 2014 (standard 4-7 days), with 22, 8 and 3 infants sampled $>7$ days during 2000-2004, 2005-2009 and 2010-2014. Median age at notification was consistently $\leq 14$ days, range falling during 2000-2004, 2005-2009 and 2010-2014 from 6 to 78, 7-52 and 7-32 days with 12 $(14.6 \%), 6(5.6 \%)$ and $5(4.3 \%)$ infants notified $>14$ days. However $18 / 123(14.6 \%)$ of infants undergoing second sampling from 2000 onwards breached the $\leq 26$-day standard for notification. By 2010-2014, the 91 infants with confirmed congenital hypothyroidism had shown favourable median age at first sample ( 5 days) with start of treatment ( 10.5 days) approaching age at notification.

Conclusion Most standards for newborn thyroid screening are being met by the Scottish programme, but there is a need to reduce age range at notification, particularly following second sampling. Strategies to improve screening performance include carrying out initial capillary sampling as close to 96 hours as possible; introducing 6-day laboratory reporting and use of electronic transmission for communicating repeat requests.

\section{INTRODUCTION}

The effective running of a Newborn Screening service depends on timely sampling of the infant: an adequate transport system between the home or hospital and the laboratory; prompt laboratory testing; and efficient communication of the results to the clinician so as to permit early review and, where appropriate, treatment. Once alerted, the clinician must ensure that the infant is seen for clinical and further laboratory assessment within days if not hours of notification.

\section{What is already known?}

- Effective newborn screening for hypothyroidism requires timely capillary sampling for thyroidstimulating hormone (TSH) measurement, efficient sample processing and prompt notification of an abnormal result.

- Previous work in Scotland has shown that when a repeat sample is requested the interval between first and second samples may exceed 3 weeks.

\section{What this study adds?}

- Initial sampling was carried out within the required standard of $\leq 7$ days in $115 / 118(97 \%)$ of referrals in Scotland between 2010 and 2014.

- Median notification age after initial sampling was 11 (9 11) days from 1990. Nevertheless, $23 / 282(8 \%)$ infants breached the $\leq 14$ day standard between 2010-2014.

- Notification age following second sampling remains relatively unsatisfactory with $14.6 \%$ patients breaching the 26-day standard 20002014. Improvement strategies include sampling at 96 hours and 6-day reporting.

In Scotland, capillary blood spot screening for thyroid-stimulating hormone (TSH) measurement has been used in the detection of primary congenital hypothyroidism since August 1979. The first survey of this screening programme showed that in the early years, late screening of infants was relatively common, ${ }^{1}$ attributable in part to the misconception that heel prick testing should be delayed until the child was on milk so as to avoid a false negative result with concurrent phenylketonuria screening. A second survey of the Scottish newborn screening programme showed improvement, but that late sampling remained a problem, particularly in inpatients. ${ }^{2}$

A further problem concerns the interval between the first and second sample when repeat sampling is necessary following a borderline test. The 2006 evaluation showed a reasonable median interval (11 days) but a wide range (up to 52 days). ${ }^{2}$ 
The purpose of the present study is to re-evaluate the screening programme by dividing the period 1980 to 2014 into seven 5 -year blocks and measuring performance against key standards including age at first blood spot testing and notification and time taken for notification after second sampling.

\section{PATIENTS AND METHODS}

The Scottish Congenital Hypothyroid database was cross checked with the Newborn Screening Laboratory and the information grouped into seven 5-year periods: 1980-1984, 1985-1989, 1990-1994, 1995-1999, 2000-2004, 2005-2009 and 2010-2014.

The data were analysed according to diagnostic category and agreed standards. Patients were assigned to four diagnostic groups: definite congenital hypothyroidism, probable congenital hypothyroidism, transient TSH elevation and status uncertain as described previously by Jones et al. ${ }^{2}$

The following standards were agreed:

1. Age at initial capillary sampling was set at 4-7 days. This is in keeping with the pregnancy and newborn quality indicators published in 2013 by Health Improvement Scotland which state that the optimum time period for blood spot sampling is between 96 and 120 hours of age and no later than 168 hours. $^{3}$

2. Interval between sampling and laboratory receipt was set at 4 days. The majority of samples are sent in prepaid first class envelopes by Royal Mail to the laboratory, with a few areas within Scotland choosing to use a courier. This standard takes account of the delay introduced by weekends during which there is no Saturday or Sunday postal delivery and no laboratory service.

3. Notification of a positive blood spot result requiring immediate referral to a clinician was set at 14 days using the capillary TSH cut-offs from 1979 to the present which have been described previously, ${ }^{4}$ with $\geq 25 \mathrm{mU} / \mathrm{L}$ whole blood from 2002 onwards. This standard allows 7 days for sampling, 4 days for sample transfer and 3 days for the laboratory to process the blood spot sample, initiate further testing when required and then communicate a positive result by telephone.

4. A 26-day standard was set for notification of a positive result following a second sample, with TSH cut-off $\geq 8 \mathrm{mU} / \mathrm{L}$ since 2002. ${ }^{4}$ This standard allows 14 days to establish that a repeat sample is required as described above, 2 days to notify the Community Child Health unit responsible that a repeat is necessary, given that some health boards do not accept communication by electronic mail, 1 day for child health to notify the midwife, 2 days for the midwife to take the sample, 4 days for transit to the laboratory and 3 days for processing.
5. No standard was set for age at starting L-T4 treatment since this decision depends on clinical assessment as well as the degree of capillary TSH elevation at the time of referral. ${ }^{4}$ However, for most infants it was expected that treatment would be on or after the day of notification, in keeping with paediatric practice in the UK. ${ }^{5}$

\section{Ethical aspects}

Since 2005, informed consent has been sought for entry onto the Congenital Hypothyroid database with retrospective consent being obtained where possible thereafter. The project was registered with the Clinical Effectiveness Department of National Health Service Greater Glasgow and Clyde as a quality improvement project.

\section{Analysis of data}

Each standard was assessed according to the seven time periods and with particular emphasis on performance of the screening programme since 2000. Data are expressed as median, mean \pm SEM, lower quartile (Q1) and upper quartile (Q3) either in table form or as box and whisker plots. Mann-Whitney testing was used to detect significant differences between 5-year blocks.

\section{RESULTS}

Between January 1980 and December 2014, the laboratory screened 2116132 newborns, of whom 919 infants were referred with capillary TSH elevation: 606 (65.9\%) with definite congenital hypothyroidism, 18 (1.9\%) with probable congenital hypothyroidism, $51(5.5 \%)$ with status uncertain, $211(22.9 \%)$ with transient TSH elevation and 33 with insufficient data.

\section{Initial capillary sampling}

Table 1 shows a significant fall in the number of infants sampled $>7$ days after $1994(\mathrm{p} \leq 0.01)$ with a plateau between 1995-1999 and 2000-2004 but a progressive decrease thereafter $(\mathrm{p}<0.001)$. Between 2000-2004, 2005-2009 and 20102014, 27, 10 and 5 infants were sampled late. Three of the five most recent infants were hospitalised at the time of sampling, including one with meningomyelocele and one with aortic coarctation.

\section{Evaluation of interval between initial sampling and laboratory receipt}

Median interval between initial testing and receipt by the laboratory was within the required 4 days throughout the study (figure 1). Between 2000 and 2004 19/150 (12.6\%) infants breached the standard, with 15/156 (9.6\%) breaching between

Table 1 Age at initial capillary sampling in Scottish infants referred with TSH elevation during seven 5-year time periods from 1980 to 2014 (required standard $=\leq 7$ days)

\begin{tabular}{|c|c|c|c|c|c|c|}
\hline Time period & Referred, n & $\begin{array}{l}\text { Median, } \\
\text { days }\end{array}$ & Tested at $4-7$ days, $n(\%)$ & Tested 8-10 days, $n,(\%)$ & Tested $>10$ days, $\mathbf{n}(\%)$ & Unknown \\
\hline 1980-1984 & 95 & 7 & $56(58.9)$ & 27 (28.4) & 11 (11.5) & 1 \\
\hline 1985-1989 & 147 & 6 & $105(71.4)$ & $27(18.3)$ & $15(10.2)$ & 0 \\
\hline 1995-1999 & 112 & 6 & $93(83.0)$ & $14(12.5)$ & $4(3.5)$ & 1 \\
\hline $2000-2004$ & 150 & 6 & $123(82.0)$ & $17(11.3)$ & $10(6.6)$ & 1 \\
\hline
\end{tabular}

n, number; TSH, thyroid-stimulating hormone. 


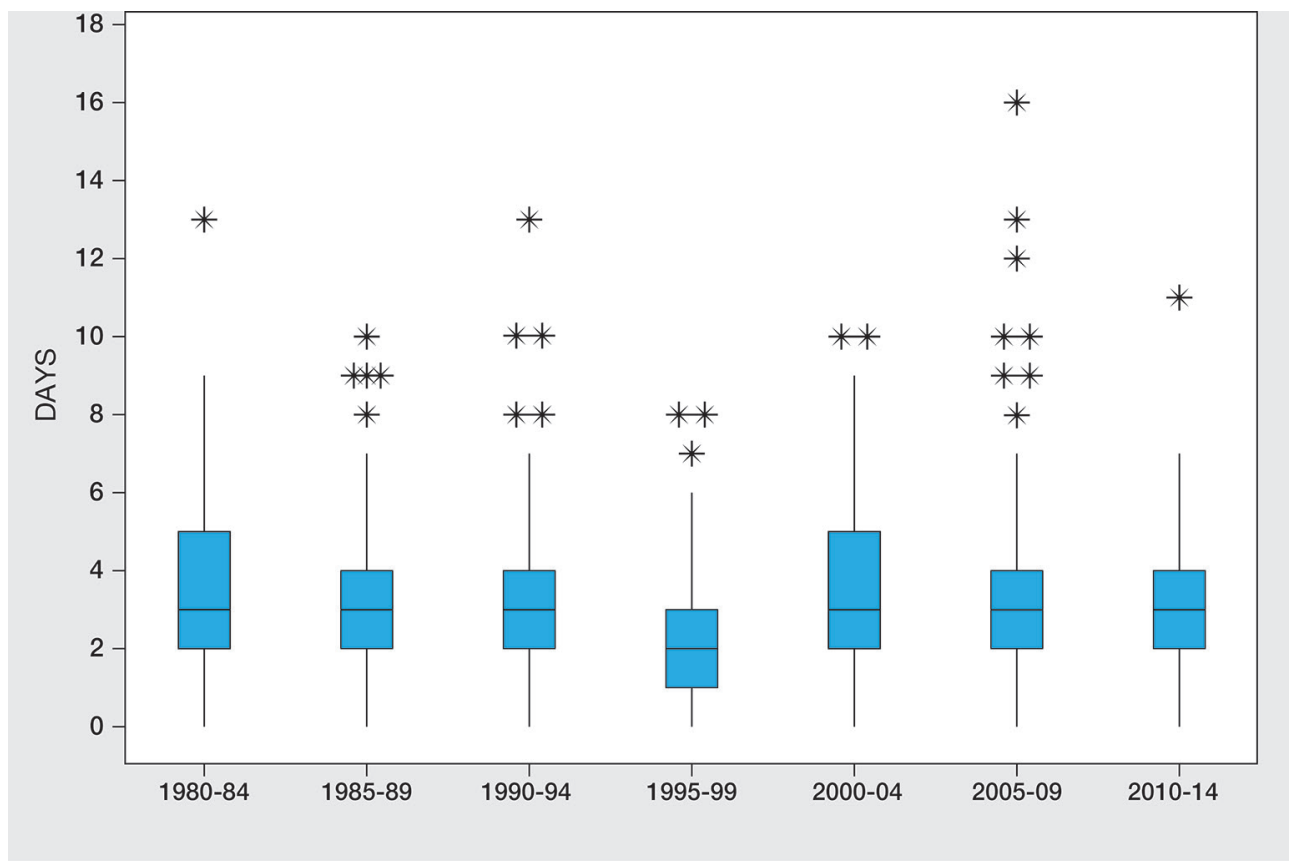

Figure 1 Box and whisker plot showing interval (days) between initial sampling and laboratory receipt in infants referred with capillary thyroidsimulating hormone elevation in Scotland between 1980 and 2014, grouped in seven 5-year time periods. Outliers are represented by asterisks.

2005 and 2009 and 20/141 (14.1\%) between 2010 and 2014. During these time periods, the number of infants with an interval exceeding 5 days fell from 25 to 21 and 6. All of the latter six infants were well, term babies who had been discharged from five different maternity units across Scotland.

\section{Age at notification following single sampling}

Median and mean ages at notification fell within the 14-day standard from 1980 to 2014 (see figure 2). Following a significant reduction from 13 and 12 days during 1980-1989 to 11 days in 1990-1994 $(\mathrm{p}=<0.001)$, age at notification remained $\leq 11$ days thereafter. During the three 5 -year periods from 2000 to 2014 age range at notification narrowed, falling from 6 to 78 to $7-52$ and then 7-32 days; with 12 (14.6\%), 6 (7.2\%) and 4 $(5.3 \%)$ infants notified $>14$ days during these periods. Reason for late notification in the 4 cases from 2010 to 14 was late sampling at 9 and 15 days in two and late receipt (day 15) in one. The fourth patient had a pre-emptive venous blood sample taken

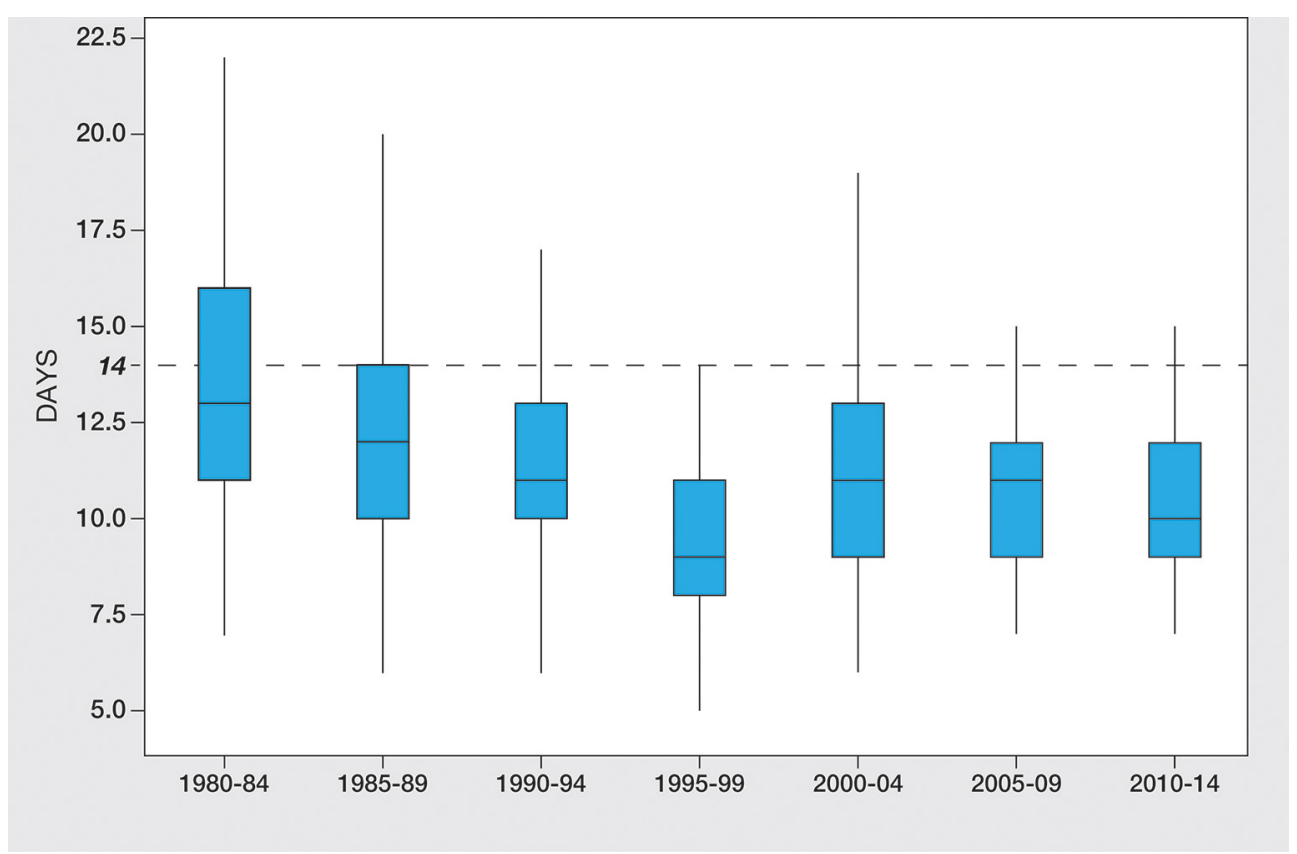

Figure 2 Box and whisker plot showing age at notification after single sampling in Scottish infants referred with capillary thyroid stimulating hormone elevation between 1980 and 2014, grouped into seven 5-year time periods. The dotted horizontal line represents the standard of 14 days for notification. 
Table 2 Age at notification (days) in 198 infants requiring second sampling (standard $\leq 26$ days)

\begin{tabular}{|c|c|c|c|c|c|c|c|}
\hline \multirow[b]{2}{*}{ Time period } & \multirow[b]{2}{*}{ Total referred } & \multirow[b]{2}{*}{ Retested (n (\%)) } & \multicolumn{2}{|c|}{ Age at notification } & \multirow[b]{2}{*}{$\begin{array}{l}\text { Notified } \\
\leq 26 \text { days ( }(\%) \text { ) }\end{array}$} & \multirow[b]{2}{*}{$\begin{array}{l}\text { Notified } \\
>26 \text { days ( }(\%))\end{array}$} & \multirow[b]{2}{*}{ Not known } \\
\hline & & & $\begin{array}{l}\text { Median } \\
\text { (range) }\end{array}$ & $\begin{array}{l}\text { Mean } \pm \text { SD } \\
(Q 1-3)\end{array}$ & & & \\
\hline 1980-1984 & 95 & $9(9.4)$ & $14.5(11-41)$ & $19.3 \pm 10.2(12.5-24.5)$ & $7(77.7)$ & $1(11.2)$ & 1 \\
\hline 1985-1989 & 147 & 28 (19) & $20.5(7-33)$ & $19.1 \pm 7.8(11-24.5)$ & $23(82.1)$ & $5(17.8)$ & 0 \\
\hline 1990-1994 & 119 & $14(11.7)$ & $22(8-31)$ & $20.4 \pm 6.7(18-24)$ & $12(85.7)$ & $2(14.2)$ & 0 \\
\hline 1995-1999 & 112 & $24(21.4)$ & $19(8-35)$ & $19 \pm 7.2(13-22)$ & $20(83.4)$ & $3(12.5)$ & 1 \\
\hline 2000-2004 & 150 & $37(24.7)$ & $21(7-50)$ & $21.4 \pm 9.3(15.5-25)$ & $28(75.6)$ & $8(21.6)$ & 1 \\
\hline 2005-2009 & 156 & $41(26.2)$ & $20(5-56)$ & $21 \pm 9.1(16-24)$ & $35(85.3)$ & $6(14.6)$ & 0 \\
\hline 2010-2014 & 140 & 45 (31.9) & $19(9-39)$ & $19.6 \pm 5.6(16-21)$ & $41(91.2)$ & $4(8.8)$ & 0 \\
\hline
\end{tabular}

This table does not show data on 31 infants tested three times during the study period.

Q1, lower quartile; Q3, upper quartile.

by the neonatal team rather than the second sample requested by the screening laboratory.

\section{Age at notification following second sampling}

Table 2 shows the increase in retesting during the study period which reached $31.9 \%$ by $2010-2014$. Of the 229 infants requiring retesting-twice in 198 and three times in 31-the median (range) birth weight and gestation was $3000 \mathrm{~g}(660-5060 \mathrm{~g})$ and 39 (25-42) weeks, with $53(23.1 \%)$ weighing <2500 g, 46 (20\%) born before 37 weeks gestation and 64 (27.9\%) known to be sick at the time of initial sampling. Congenital hypothyroidism was confirmed in 74 (32.3\%) of these infants, with transient TSH elevation in $83(36.2 \%)$ and status still uncertain in $72(31 \%)$.

During 2000-2004, 2005-2009 and 2010-2014, the numbers of infants sampled twice who breached the 26-day standard were $8 / 37$ (21.6\%), 6/41 (14.6\%) and 4/45 (8.8\%), 4 with confirmed congenital hypothyroidism, 10 with transient TSH elevation and 4 with status uncertain.

\section{Screening trends in infants with definite and probable congenital hypothyroidism}

Table 3 shows an improvement in median age and a narrowing of age range at initial sampling between 1980-1984 and 2010-2014. Median age at start of treatment improved significantly from 16 and 13 days between 1980 and 1989 down to 11-12 days during 1990-2004 ( $<<0.001)$ with a smaller and non-significant fall to 11.5 and 10.5 days during 2005-2009 and $2010-2014$ as it approached the day of notification. From 2002, the year that the current autoDelfia TSH assay came into use, 21 infants started treatment $>26$ days of whom 10 had definite congenital hypothyroidism, 8 transient TSH elevation and 3 status uncertain. Testing had been carried out twice in 14 , three times in 4 and once in only 3 . Median (range) birth weight was $3.07(0.69-4.18 \mathrm{~kg})(7$ infants $<2500 \mathrm{~g})$ and gestation 39 (26-42) weeks (seven infants $<37$ weeks) and 8 infants were logged as 'sick'. Thirteen infants started treatment aged 27-40 days, attributable to repeat testing alone (3), surveillance of low grade TSH elevation (1) and both repeat testing and surveillance (9). Four infants started treatment aged between 41 and 55 days owing to delayed initial sampling at 31 days in an extremely sick, preterm and low birthweight infant (birth weight $690 \mathrm{~g}$ at 29 weeks gestation) in whom capillary TSH was $127 \mathrm{mU} / \mathrm{L}$; delayed repeat sampling at 39 days in an infant with multiple congenital malformations; and late notification at 31 and 49 days in two preterm infants ( 31 and 27 weeks) who had been tested three times. Four infants started treatment very late at 81, 94, 127 and 200 days, reflecting prolonged surveillance of modest TSH elevation.

\section{DISCUSSION}

The goal of newborn screening for congenital hypothyroidism is to ensure that affected infants start treatment as soon as possible, so that neurological impairment is either prevented or minimised. The European Society for Paediatric Endocrinology (ESPE) consensus paper of Léger et al states that thyroxine treatment should be started as soon as possible and not later than within the first 2 weeks of life. ${ }^{6}$ This recommendation was graded as a 'strong' but with only 'moderate' evidence, using the scheme of Swiglo $\mathrm{et}^{\mathrm{al}} \mathrm{l}^{7}$ since the value of starting treatment at 14 days rather than a week later remains unproven. However, starting thyroxine beyond 21 days has been shown to affect outcome, ${ }^{8}$

Table 3 Age (days) at initial testing, notification and start of treatment in 623 of 624 infants with true congenital hypothyroidism referred by Scottish Screening laboratory 1980-2014

\begin{tabular}{|c|c|c|c|c|c|c|}
\hline \multirow[b]{2}{*}{ Time period } & \multicolumn{2}{|c|}{ Age at initial sampling } & \multicolumn{2}{|c|}{ Age at notification } & \multicolumn{2}{|c|}{ Age at start of treatment } \\
\hline & $\begin{array}{l}\text { Median } \\
\text { (range) }\end{array}$ & $\begin{array}{l}\text { Mean } \pm \text { SEM } \\
(Q 1-3)\end{array}$ & $\begin{array}{l}\text { Median } \\
\text { (range) }\end{array}$ & $\begin{array}{l}\text { Mean } \pm \text { SEM } \\
(Q 1-3)\end{array}$ & $\begin{array}{l}\text { Median } \\
\text { (range) }\end{array}$ & $\begin{array}{l}\text { Mean } \pm \text { SEM } \\
(Q 1-3)\end{array}$ \\
\hline $1980-1984 n=79$ & $7(4-56)$ & $7.8+/-5.9(6-8)$ & $13(5-59)$ & $14.4+/-6.5(11-17)$ & $16(8-313)$ & $21+/-35.3(13-19)$ \\
\hline $1985-1989 n=91$ & $6(4-35)$ & $6.7+/-3.4(5-7)$ & $12(8-43)$ & $12.9+/-5.6(10-14)$ & $13(8-212)$ & $17.4+/-23(11-16)$ \\
\hline $1990-1994 n=85$ & $6(4-49)$ & $7.2+/-5(5-7.5)$ & $11(5-54)$ & $13.3+/-9(10-13)$ & $12(2-195)$ & $16.5+/-22.7(10-15)$ \\
\hline $1995-1999 n=85$ & $6(1-13)$ & $5.9+/-1.6(5-7)$ & $10(5-38)$ & $11.2+/-5.6(8-12)$ & $11(1-177)$ & $16.8+/-27(8-13)$ \\
\hline $2000-2004 n=90$ & $6(3-17)$ & $6.1+/-1.6(5-7)$ & $11(3-31)$ & $12+/-4.2(10-13)$ & $12(3-200)$ & $17.4+/-27.4(10-14)$ \\
\hline $2005-2009 n=102$ & $5(1-12)$ & $5.2+/-1.2(5-6)$ & $11(5-56)$ & $12.5+/-7.1(9-13)$ & $11.5(1-94)$ & $13.4+/-10(10-14)$ \\
\hline $2010-2014 n=91$ & $5(4-15)$ & $5+1-1.2(4-5)$ & $10(7-31)$ & $11.7+/-4.6(9-12)$ & $10.5(1-48)$ & $11.9+/-6(9-13)$ \\
\hline
\end{tabular}

Q1, lower quartile; Q3, upper quartile. 
while infants with athyreosis will display unwanted symptoms such as jaundice and feeding difficulties within the first week of life and hence benefit from early treatment. ${ }^{9}$

A prerequisite of starting thyroxine treatment promptly is timely heel prick sampling. The present study shows that virtually all infants in Scotland are now tested within the Scottish standard of 4-7 days, with median age at first sampling falling to 5 days, compared with the 6 days reported in the latter half of the 2006 audit by Jones et al. ${ }^{2}$ There has also been a steady drop in the numbers of infants breaching the 7-day standard, with only five during 2010-2014. It is noteworthy that three of these infants were sick and/or had prolonged hospital stay, indicating the need for continuing vigilance in hospitalised infants.

The standard chosen for age at initial sampling in Scotland contrasts with the ESPE guidelines which state that the best window of opportunity for testing babies is $48-72$ hours of age. ${ }^{6}$ In fact, the most recent Scottish guidelines specify that sampling should take place 'as soon as possible after 96 hours' (4 days), ${ }^{10}$ while the English Newborn Blood Spot Screening Programme guidelines from September 2015 state that screening should be on day 5 of life. ${ }^{11}$ The rationale of testing after 48 hours of life is to avoid the effect of the postnatal TSH surge described by Fisher $e t ~ a l .{ }^{12}$ Bringing forward the mean day of sampling from day 5 to day 3 in Scotland would improve the performance of the thyroid screening programme as well as conferring the added benefit of early detection of inborn errors of metabolism such as medium-chain acyl-CoA dehydrogenase deficiency ${ }^{13}$ and maple syrup urine disease. However, this would have major logistic implications, particularly concerning immunoreactive trypsinogen sampling for cystic fibrosis which is currently recommended at 5 days in the UK ${ }^{14}$ although carried out earlier elsewhere, for example, at 24-36 hours in Michigan. ${ }^{15}$

As shown in figure 1, the interval between sampling and laboratory receipt processing of samples was consistently within the standard of 4 days throughout the study period while age at notification following single sampling also showed a favourable trend (see figure 2). Test results for notification were seen during 2010-2014 when median age was down to 10 days and range reduced to 7-32 days with only four infants notified after the 14-day standard. By contrast, the timelines for repeat sampling are less satisfactory. Thus, 18/123 (14.6\%) of infants undergoing second sampling during the past 15 years have breached the $\leq 26$ day standard for notification. This standard is in fact more generous than the 2013 UK Initial Clinical Referral Standards and Guidelines which sets 14 and 21 days as achievable standards for starting treatment with L-T4 following initial and repeat sampling by 14 days after a single sample and 21 days after a repeat blood sample. ${ }^{16}$

Concerning age at starting treatment it should be noted that while median/upper quartile fell from 16/19 during 19901994 to 10.5/13 during 2010-2014, some patients started thyroxine well after the neonatal period throughout the study (see table 3). Analysis of the 21 patients starting treatment late (>26 days) from 2002 onwards shows the key factors to be: a predominance of preterm and low birthweight infants with modest initial capillary TSH prompting repeat testing (particularly when three tests are requested); late retesting (and in the case of one infant very late initial testing) in the context of extreme prematurity and neonatal sickness; and modest TSH elevation on retesting, resulting in surveillance rather than prompt treatment. In Scotland, a borderline result (8-25 $\mathrm{mU} / \mathrm{L}$ ) is notified by the screening laboratory to the Community Child Health $(\mathrm{CCH})$ unit within each Scottish Health Board. While most $\mathrm{CCH}$ units accept electronic mail, some will only accept Royal Mail requests. The CCH unit then has to identify the appropriate midwifery team. Each unit has its own system for notifying the midwifery service, most units preferring notification by facsimile. There is no nationally agreed deadline set for the midwives to collect the repeat sample.

Based on the findings of this study, we recommend the following changes to improve the screening programme in Scotland, particularly concerning the problem posed by repeat sampling:

1. Bringing the age at initial capillary sampling as close to 96 hours of life as possible, consistent with the Scottish guidelines. ${ }^{12}$

2. Introducing 6-day laboratory reporting so that results are transmitted on Saturdays, as well as weekdays, this proposal is currently awaiting approval from the commissioners of newborn screening in Scotland.

3. Insisting on electronic transmission of repeat requests from Screening Laboratory to $\mathrm{CCH}$ and from $\mathrm{CCH}$ to community midwife.

A further measure to improve the efficiency of repeat testing would be to fund a liaison nurse practitioner, based in the screening laboratory. This measure would accelerate the time taken to communicate the need for repeat sampling, oversee timely repeat sampling in the community and prompt laboratory receipt/processing and rapid communication of the result to the clinician.

Acknowledgements We thank all the Scottish paediatricians for their generous support of the Congenital Hypothyroid database and for responding positively to numerous requests for follow-up information.

Contributors CM and YO came as visiting fellows during the Spring of 2014 to collect data for the study in close collaboration with JJ, data manager for the thyroid screening database and SS in the Newborn Screening Department. In Spring 2016, CM returned to complete data collection for 2014 so that the study could comprise seven complete 5 -year blocks. CM was aided by MF from Newborn Screening during SS' maternity leave. AM oversaw and approved the project with MD. MD wrote the body of the paper, incorporating data which had been collated and analysed by CM, YO and JJ. All authors read and approved the paper.

Competing interests None declared.

Patient consent Detail has been removed from this case description/these case descriptions to ensure anonymity. The editors and reviewers have seen the detailed information available and are satisfied that the information backs up the case the authors are making.

Provenance and peer review Not commissioned; externally peer reviewed.

Open Access This is an Open Access article distributed in accordance with the Creative Commons Attribution Non Commercial (CC BY-NC 4.0) license, which permits others to distribute, remix, adapt, build upon this work non-commercially, and license their derivative works on different terms, provided the original work is properly cited and the use is non-commercial. See: http://creativecommons.org/ licenses/by-nc/4.0/

(c) Article author(s) (or their employer(s) unless otherwise stated in the text of the article) 2017. All rights reserved. No commercial use is permitted unless otherwise expressly granted.

\section{REFERENCES}

1 Ray M, Muir T, Kennedy R, et al. An audit of congenital hypothyroidism in Scotland 1979-1993. Arch Dis Child 1997;76:411-5.

2 Jones JH, Mackenzie J, Croft GA, et al. Improvement in screening performance and diagnosis of congenital hypothyroidism in Scotland 1979-2003. Arch Dis Child 2006;91:680-5.

3 Indicators for Pregnancy and Newborn Screening. Health Improvement Scotland 2013. http://www.healthcareimprovementscotland.org/our_work/reproductive, maternal_child/programme_resources/pns_indicators.aspx

4 Pokrovska T, Jones J, Shaikh MG, et al. How well does the capillary thyroid-stimulating hormone test for newborn thyroid screening predict the venous free thyroxine level? Arch Dis Child 2016;101:539-45. 
5 Jones JH, Donaldson MD. Audit of initial management of congenital hypothyroidism in the United Kingdom--comparison of UK practice with European and UK guidelines. J Pediatr Endocrinol Metab 2009;22:1009-16.

6 Léger J, Olivieri A, Donaldson M, et al. Gary Butler on behalf of ESPE-PES-SLEP- JSPEAPEG-ISPAE, and the Congenital Hypothyroidism Consensus Conference Group. European Society for Paediatric Endocrinology Consensus Guidelines on Screening, Diagnosis and Management of Congenital Hypothyroidism. J Clin Endocrinol Metab 2014;21:jc20131891.

7 Swiglo BA, Murad MH, Schünemann HJ, et al. A case for clarity, consistency, and helpfulness: state-of-the-art clinical practice guidelines in endocrinology using the grading of recommendations, assessment, development, and evaluation system. J Clin Endocrinol Metab 2008;93:666-73.

8 Boileau $\mathrm{P}$, Bain P, Rives $\mathrm{S}$, et al. Earlier onset of treatment or increment in LT4 dose in screened congenital hypothyroidism: which as the more important factor for IQ at 7 years? Horm Res 2004:61:228-33.

9 Donaldson M, Jones J. Optimising outcome in congenital hypothyroidism; current opinions on best practice in initial assessment and subsequent management. current opinions on thyroid disease in childhood. J Clin Res Pediatr Endocrinol 2013;5:13-22.

10 Scottish Newborn Bloodspot Screening Programme; Sampling guidelines September 2015 version 1.0. http://www.nsd.scot.nhs.uk/Documents/Newborn\%20Bloodspot\% 20Sampling\%20Guidelines\%202015\%20v1.pdf
11 NHS guidelines for Newborn Blood Spot Sampling Draft Version 0.5/September 2015. https://www.gov.uk/government/uploads/system/uploads/attachment_data/file/ 457885/Guidelines_for_Newborn_Blood_Spot_Sampling_2015_v0_5.pdf

12 Fisher DA, Dussault JH, Sack J, et al. Ontogenesis of hypothalamic-pituitary-thyroid function and metabolismin man, sheep, and rat. Rec Prog Horm Res 1977;33:59-116.

13 Dyack S. Expanded newborn screening: lessons learned from MCAD deficiency. Paediatr Child Health 2004;9:241-3.

14 A Laboratory Guide to Newborn Screening in the UK for Cystic Fibrosis. NHS Screening Programmes. 4th ed, 2014. https://www.gov.uk/government/uploads/ system/uploads/attachment_data/file/338922/SACN_RCPCH_Application_of_WHO_ Growth_Standards.pdf

15 Korzeniewski SJ, Young WI, Hawkins HC, et al. Variation in immunoreactive trypsinogen concentrations among Michigan newborns and implications for cystic fibrosis newborn screening. Pediatr Pulmonol 2011;46:125-30.

16 UK Newborn Screening Programme Centre (2013) Congenital Hypothyroidism: Initial Clinical Referral Standards and Guidelines. In: A Laboratory Guide to Newborn Screening in the UK for Congenital Hypothyroidism (pp29-35). https://www.gov.uk/ government/publications/congenital-hypothyroidism-screening-laboratory-handbook 